\title{
RUSSIAN-CULTURE-ORIENTED DISCOURSE OF ENGLISH: PROSPECTS OF CORPUS RESEARCH
}

\author{
Elena V. Beloglazova \\ Saint Petersburg State University of Economics, Saint Petersburg, Russia \\ Viktor V. Kabakchi \\ Saint Petersburg State University of Economics, Saint Petersburg, Russia
}

\begin{abstract}
The present paper deals with the processes defining the development of the English language as a means of international communication in the era of globanglization, i.e. the establishment of English as the global lingua franca. The spreading practice of applying the language to external cultures predetermines the need of adapting it to new situations and tasks. The above said adaptation results in the emergence of variants of English of international communication, characterized by secondary cultural orientation. One of these variants is the English, oriented towards the Russian culture, which is the result of the adaptation of English to the tasks of dealing learning with external culture.

The research highlighted here focuses on the Russian-culture-oriented discourse, aiming at identifying its markers - xenonymic Russianisms - on lexical, syntactic and stylistic levels. Apart from most evident cultural terms, Russianisms may take the form of literary allusions and quotations, proverbs and idioms, rhetorical and cognitive patterns. Thus, the formation of foreign-culture-oriented English is viewed in the light of expanding the language expressive potential, its development and enrichment.

The research is based on a complex methodology, combining traditional methods of linguistic analysis with corpus technologies aimed at verifying the hypotheses and reducing the subjectivism. For example, applying national corpora allows revealing the place of the Russian-culture-oriented discourse under study within the general discursive space of the English language by identifying the frequency and the mode of functioning of its markers, in particular in different national variants of the English language, and possibly in the evolutionary aspect.

Key words: culturonym, linguoculture, external linguocultural context, cultural orientation, primary cultural orientation, secondary cultural orientation, language of secondary cultural orientation, corpus linguistics.

Citation. Beloglazova E.V., Kabakchi V.V. Russian-Culture-Oriented Discourse of English: Prospects ofCorpus Research. Vestnik Volgogradskogo gosudarstvennogo universiteta. Seriya 2, Yazykoznanie [Science Journal of Volgograd State University. Linguistics], 2018, vol. 17, no. 3, pp. 49-59. (in Russian). DOI: https://doi.org/10.15688/ jvolsu2.2018.3.5
\end{abstract}

УДК 811.111:008

Дата поступления статьи: 13.05.2018

ББК 81.432.1-006

Дата принятия статьи: 11.06.2018

\section{ДИСКУРС АНГЛОЯЗЫЧНОГО ОПИСАНИЯ РУССКОЙ КУЛЬТУРЫ: ПЕРСПЕКТИВЫ КОРПУСНОГО ИССЛЕДОВАНИЯ}

\author{
Елена Владимировна Белоглазова \\ Санкт-Петербургский государственный экономический университет, г. Санкт-Петербург, Россия \\ Виктор Владимирович Кабакчи \\ Санкт-Петербургский государственный экономический университет, г. Санкт-Петербург, Россия
}

Аннотация. В статье рассматриваются факторы, определяющие развитие английского языка международного общения на этапе «глобанглизации» - установления английского языка в роли глобальной lingua 
franca. Распространяющаяся практика использования языка во вторичной культурной ориентации предопределяет необходимость его адаптации к новым ситуациям и задачам, результатом которой являются варианты английского языка международного общения, ориентированные на разные культуры. Один из таких вариантов обращен к русской культуре, что обусловило выбор его в качестве объекта исследования.

В статье выявляется специфика дискурса англоязычного описания русской культуры как результат адаптации английского языка при его вторичной культурной ориентации. Протекающие в нем процессы рассматриваются в свете расширения его выразительных возможностей, развития и обогащения. В основе исследования лежит комплексная методика, сочетающая классические лингвистические инструменты анализа с корпусными технологиями, которые служат для верификации выдвигаемых гипотез и преодоления субъективизма анализа.

Работа с национальными корпусами позволяет оценить место изучаемого дискурса в общем дискурсивном пространстве современного английского языка путем отслеживания частотности и функционирования его суперструктурных маркеров, в том числе в разных национальных вариантах английского языка и диахроническом аспекте.

Ключевые слова: культуроним, лингвокультура, инолингвокультурный контекст, культурная ориентация, первичная культурная ориентация, вторичная культурная ориентация, язык вторичной культурной ориентации, корпусная лингвистика.

Цитирование. Белоглазова Е. В., Кабакчи В. В. Дискурс англоязычного описания русской культуры: перспективы корпусного исследования // Вестник Волгоградского государственного университета. Серия 2 , Языкознание. - 2018. - Т. 17, № 3. - C. 49-59. - DOI: https://doi.org/10.15688/jvolsu2.2018.3.5

\section{Введение}

Язык, если он естественный, существует в тесной связи с исторически обслуживаемой им культурой, образуя с ней диалектическое единство - лингвокультуру - и выступая в качестве семиотической «надстройки» над ее «фундаментом».

Тесная связь, можно даже сказать двуединство, воплощается в специфичности языка, значительная часть лексикона в котором является культурно отмеченной, то есть в нем вырабатывается специальная номенклатура культуронимы.

Вместе с тем ни один язык, менее всего международный, не может замыкаться исключительно на своей родной культуре и вынужден обращаться к другим. Таким образом, относительно любого языка представляется возможным говорить о внутренней культу$p e$ - той, к которой он обращен изначально, то есть о его первичной культурной ориентащии, и о внешних для него культурах, с которыми его связывает вторичная культурная ориентация.

В статье предпринята попытка выявить, каким образом обращение к внешней культуре влияет на язык описания, а также к каким средствам прибегает язык для описания того, что в нем не имеет даже названия.

\section{Методика}

Объектом предпринятого исследования является дискурс англоязычного описания русской культуры - особая функциональная разновидность английского языка международного общения, специфику которой предопределяет ее вторичная культурная ориентация.

В основе изучения лежит разработанный В.В. Кабакчи метод опосредованного наблюдения и экстраполяции, который фактически является разновидностью сравнительно-сопоставительного метода [Кабакчи, 2007]. Алгоритм исследования включает следующие этапы:

1) отбор корпуса аутентичных текстов англоязычного описания русской культуры;

2) анализ этого материала (в широком смысле слова), направленный на выявление средств вербализации внешнекультурных реалий - ксенонимов;

3) когнитивно-семантический анализ ксенонимов в соотношении с лежащими в основе их появления фактами исходной лингвокультуры - идионимами;

4) дискурсивный анализ текстового корпуса.

Традиционные методы лингвистического анализа, перечисленные выше, дополняются корпусными, которые выступают «надежными инструментами верификации гипотез, преодолевая субъективизм интерпретативных 
качественных методов, основанных на интуиции» [Ильинова, Кочетова, 2017, с. 48-49].

Эффективность корпусного подхода проявляется, по мнению Е.Е. Голубковой, в установлении частотности использования языковых единиц и определении прототипического значения как на уровне слов, так и на уровне морфем [Голубкова, 2012, с. 93, 96]. Этим и обусловлено использование корпусных методов в нашем исследовании.

\section{Инолингвокультурный контекст в дискурсе англоязычного описания русской культуры}

Описание иноязычной культуры неизбежно включает элементы инолингвокультуры, которые мы называем инолингвокультурным контекстом. Он характеризуется введением в текст на языке описания при его вторичной культурной ориентации языковых реалий внешней культуры.

В приведенном ниже фрагменте инолингвокультурный контекст (здесь и далее выделено нами. $-E$. Б., В. K.) представлен значительным количеством элементов, которые имеют в нем большую смысловую нагрузку:

(1) Second, unofficial literature written within the Soviet Union came to include works circulated illegal in typewritten copies (samizdat), works smuggled abroad for publication (tamizdat), and works written "for the drawer", or not published until decades after they were written ("delayed" literature) (Encyclopedia Britannica: Soviet Literature: Tamizdat).

Вкрапления инолингвокультурного контекста могут быть более или менее заметными. Например, если транслитерированное заимствование культуронима (см. в примере выше tamizdat и samizdat) является очевидно чужеродным и относится к внешней лингвокультуре, то кальки ("for the drawer" и "delayed literature") читатель может попытаться проинтерпретировать в рамках внутренней лингвокультуры. Поскольку калькирование строится на комбинировании имеющихся в языке морфем, заимствование-калька является осмысленным в рамках языка описания и может соотноситься с фактом внутренней культуры. Эта возможность ложной культурной атрибуции заставляет авторов текстов вторичной культурной ориентации вводить дополнительные средства остранения - в приведенном примере этой цели служат кавычки.

Таким образом, элементы инолингвокультурного контекста не только неизбежны при иноязычном описании культуры и служат для ее адекватного описания, но также являются частью стратегии порождения текста вторичной культурной ориентации. Эта стратегия направлена на дистанцирование от первичной культурной ориентации за счет дифференциации языковых средств, используемых для описания внутренней и внешней культуры.

\section{Изменчивость}

\section{инолингвокультурного контекста}

в дискурсе англоязычного описания

\section{русской культуры}

Граница между элементами инолингвокультурного контекста и собственной лексикой языка описания может быть размытой. Поскольку контакт языков и их взаимопроникновение как неизбежное следствие этого контакта - естественный путь развития языков, синхронный срез лексики любого языка будет содержать следы взаимопроникновений в виде элементов инолингвокультурного контекста. При этом с течением времени эффект чужеродности в них может сглаживаться или вовсе утрачиваться в процессе ассимиляции ксенонимов.

Рассмотрим следующий пример:

(2) «Czars»

October revolutions just ain't what they used to be

It was 92 years, almost to the day, since the Bolsheviks stormed the Winter Palace. Sens. Joe Lieberman (I-Conn.) and Susan Collins (R- Maine), as fine a duo as Lenin and Trotsky, presided over the Senate Homeland Security and Governmental Affairs Committee, which for a couple of hours Thursday morning seemed more like the Council of People's Commissars (Washington Post, October 23, 2009).

Статья посвящена американским внутриполитическим проблемам и адресована сугубо американскому читателю, то есть ее нельзя охарактеризовать как текст иноязычного описания русской культуры. Тем не менее фрагмент изобилует культуронимами-русизмами (Czars, Council of People's 
Commissars, Lenin, Trotsky, Bolsheviks, Winter Palace), введенными в него на правах единиц словаря английского языка.

В этом ряду примечателен русизм czar. Исходный культуроним цุарь раздвоился в английском языке на tsar и czar, первое слово типично для британского варианта языка, второе - для американского. Несмотря на то, что эти единицы встречаются в обоих стандартах английского языка, отмеченный выше семантический сдвиг (ассимиляция) наблюдается регулярно только у лексемы $c z a r$ и только в американском варианте.

Например, в British National Corpus czar встречается 40 раз и единственным аномальным для него сочетанием является “decency czar"; причем на аномальность указывает графическое выделение словосочетания кавычками (BNC: czar). Лексема tsar, как мы отметили, типична для британского английского. Она встречается 580 раз, преимущественно в прямом значении русизма с типичной коллокацией last, crowned, reign. Контекст, когда рассматриваемое слово выражает то же значение, что и в (2), единичен: в нем словом tsar назван некто William Bennett, «бушующий» (thundered) перед Конгрессом при обсуждении темы наркотиков (BNC: tsar).

В корпусе американского английского языка обе рассматриваемые нами лексемы характеризуются более высокой частотностью. Однако если $t s a r$ традиционно используется в значении, отражающем российские реалии, сочетаясь с Russian, last, under, reign и т. п. (COCA: tsar), то czar регулярно употребляется в нетипичных контекстах. На семантический сдвиг указывают коллокаты, список которых открывают drug (252), new (64), former (38), car (36), house (30), AIDS (28), и лишь на седьмом месте находится Russian (27) (COCA: czar). В отличие от первичного культуронима, чаще всего встречающегося в конструкции «tsar + имя собств.» (напр. Tsar Alexander), вторичный является частью конструкции «имя нариц. + tsar», в которой существительное в препозиции номинирует сферу деятельности референта.

Отметим, что вне связи с исходной лингвокультурой могут использоваться не только ксенонимы-русизмы, но и ксенонимы из других языков, например, японизмы:
(3) Do not open your kimono about your personal life, because people will take advantage of your weaknesses (COCA: kimono).

В данном случае выражение to open one's kimono означает «раскрывать личные сведения». Оно стало широко использоваться в деловом дискурсе в значении «раскрытие внутрикорпоративной информации потенциальному партнеру».

Приведенные примеры позволяют сделать важное наблюдение: лексикон современного английского языка неоднороден и содержит следы инолингвокультурных контекстов всех тех языков, с которыми он вступал во взаимодействие на протяжении своей долгой истории, что особенно заметно в лексико-семантических полях «история» (tsar / czar, boyar, Decembrist); «география» (steppe, Siberia, chernozyom / black earth); «религия» (starets, yurodiviy, domovoy); «литература» (Anna Karenina, Chekhov, Chechovian, "Dead Souls»); «искусство» ("Swan Lake», the Mighty Handful / the Russian Five / the Mighty Five, the Bolshoi (Theatre)); «кулинария» (pelmeni, blini, borsch); «быт» (propiska, palaty, tapochki). Указанную генеалогическую неоднородность английского лексикона наглядно иллюстрирует словарь тезаурусного формата.

В качестве иллюстрации рассмотрим лексико-семантическое поле HOUSE, как оно представлено в словаре-тезаурусе (Roget's International Thesaurus..., 1922). Это поле включает большое количество ксенонимов различного происхождения. Причем, во-первых, некоторые из этих культуронимов приведены обычным прямым шрифтом, а некоторые курсивом, во-вторых, какие-то из них снабжены пометой об их лингвокультуре-источнике, а какие-то - нет.

Очевидно, отдельные из приведенных в словаре культуронимы уже настолько ассимилировались, что автор словаря посчитал возможным не указывать их происхождения. Такие слова не имеют ни графического выделения курсивом, ни специальных помет: harem, seraglio, zenana, wigwam, jacal, tepee, topek, dorp, ghetto, piazza, plaza, khan, villa.

Некоторые ксенонимы еще не утратили связи с исходной лингвокультурой, хотя воспринимаются как полноценные элементы ан- 
глийского словаря: hacienda [Sp. Amer.], chummery [esp. Anglo-Indian], kraal [S. Africa], rancho [Sp. Amer.], dak bungalow [India], shebeen [Irish and Scot.], the Hills [India]. В тезаурусе они графически не выделены, но сопровождаются сведениями о происхождении. В ряде случаев составитель не уверен в статусе конкретного ксенонима и приводит сразу два варианта его представления: chalet or chalet [F.], igloo or iglu [Eskimo], bustee or basti [Hind.].

Культуронимы наибольшей степени экзотичности даются в тезаурусе курсивом, указывающим на их чужеродность, в сочетании с маркировкой их происхождения: posada [Sp.], lares et penates [L.], dulce domum [L.], kala jagah [Hind.], chalet [F.], rus in urbe [L.], casa [Sp., Pg. and It.], Château [F.], alameda [Sp.], place [F.], estaminet [F.].

Словарь языка в целом и инолингвокультурный пласт в частности подвижны. Изменения культуронимов связаны с состоянием конкретного языка, на которое влияют такие факторы, как международная ситуация, экономическое и культурное развитие общества, географическая близость к другим языкам и т. д.

Особенно нестабильной является последняя из указанных выше групп, воспринимаемая как экзотизмы и тесно связанная с исходной лингвокультурой. Из одиннадцати культуронимов этого статуса, приведенных в тезаурусе, век спустя актуальны только три: estaminet, casa, château. Актуальность estaminet весьма условна, поскольку в British National Corpus это слово встречается лишь три раза, причем только в декоративной функции.

Согласно British National Corpus ксеноним casa использован в 47 различных текстах, преимущественно в составе имен собственных (Casa de Las Conchas, la Casa de la Vall), грамматическая структура которых свидетельствует о том, что слово casa полностью не ассимилированно и семантически непрозрачно. Поэтому оно в ряде случаев дублируется калькой:

(4) Ahead of you as you walk along the length of the piazza is the Casa del Manzoni, Manzoni's house (BNC: casa).

Ксеноним château оказался более частотным (246 употреблений в 63 различных текстах), и анализ контекстов, в которых он встречается, показывает, что этот культуроним постепенно утрачивает связь с исходной лингвокультурой, а также меняет свое значение:

(5) 'It was a mere chateau in the Italian style of architecture,' wrote Osbaldeston of Ebberston, 'and not large enough for us; but we took it (BNC: chateau).

Из приведенного фрагмента явствует, что вопреки данным словарей, фиксирующих значение «a castle or large country house in France» (LDCE: chateau), сегодня для англоговорящего château не обязательно замок, французский, большой, великолепный.

В более стабильной категории ассимилировавшихся инолингвокультурных заимствований также произошли заметные изменения:

- некоторые культуронимы настолько продвинулись к ядру лексикона, что легли в основу новообразований: cp. garage + bungalow $=$ garalow;

- часть их отодвинулась ближе к периферии английского словаря; об этом свидетельствует их низкая частотность и слабая семантическая прозрачность (ср. zenana, seraglio);

- ряд культуронимов-заимствований вышел из употребления (ingleside, jacal, topek, bustee or basti, dorp, khan).

Помимо отмеченных изменений, лексико-семантическое поле HOUSE в современном английском языке обогатилось заимствованиями, не отмеченными в словаре начала $\mathrm{XX}$ в.: palazzo (356 вхождений в $\mathrm{BNC}$ ), dacha (45 вхождений в BNC), yurt (30 вхождений в $\mathrm{BNC})$, lavvu (8 вхождений в $\mathrm{BNC})$.

В рассматриваемом лексико-семантическом поле можно отметить увеличение употребительности ксенонимов-русизмов. Например, в BNC, фиксирующем данные не позднее конца XX в., русизм dacha встречался 45 раз, то в его американском аналоге COCA, отражающем новейшие тенденции в языке, отмечено 286 его употреблений.

\section{Маркеры \\ инолингвокультурного контекста \\ в дискурсе англоязычного описания русской культуры}

Инолингвокультурный контекст может быть представлен не только отдельными сло- 
вами, что показано в предыдущих разделах, но и другими языковыми единицами, прежде всего, идиоматикой. Фразеологизмы, пословицы, поговорки отличаются компактностью, яркостью, эмоциональной насыщенностью и ярко выраженным национальным колоритом [Кунин, 1964, с. 3], что делает их незаменимыми при описании культуры.

Фразеологизмы активно используют авторы путеводителей, публицистических и художественных произведений:

(6) Being curious can get you into trouble. We often tell people this in an attempt to warn someone not to ask too many questions about a certain topic, or to stop prying into the affairs of somebody else. However, Russians have a very different way of portraying the same meaning. "Lyubopytnoi Varvare na bazare nos otorvali". The translation of this peculiar turn of phrase is 'Nosy Barbara had her nose torn off at the market', referring to the way in which being intrusive and nosy will only result in an unpleasant situation for you. In other words, as the proverb goes in English, 'curiosity killed the cat' (St. Petersburg in Your Pocket, FebruaryMarch, 2015, p. 59).

(7) As a Russian proverb puts it, "You never value what you have until you lose it" (Time, 06.01.1992).

(8) Reagan ... bubbled his favourite Russian phrase, 'Trust but verify' ... (Time, 19.12.1990).

(9) ... illustrating it by the proverb, 'He wishes to climb the fir tree but is afraid to scrape his shins' (Nabokov V. Pnin).

Как показывают приведенные примеры, наиболее распространенным способом введения фразеологизма является калькирование, обычно сопровождающееся вводным оборотом, настраивающим читателя на восприятие чужеродной идиоматики (as a Russian proverb puts it ...; his favourite Russian phrase; consider the wise Russian saying и т. п.).

Отсутствие подобного указания может затруднить восприятие текста и / или исказить его смысл. Например:

(10) 'Go? Where?'- 'Whither, dear Eleanor, the Tsar himself's obliged to foot it, ' he intoned, accelerating rapidly for the glass door (Lear J. Death in Leningrad).

Фраза Tsar himself's obliged to foot it не всеми может быть опознана как калька русского выражения «туда, куда сам царь пешком ходит».
В нашем материале имеются примеры, в которых англоязычные авторы используют русские пословицы при описании «своей» действительности. Например, размышляя в апреле 2008 г. о том, что президенту Бушу-младшему еще восемь месяцев управлять страной, журналист вспоминает русскую пословицу о рыбе, которая гниет с головы:

(11) ...consider the wise Russian saying, "The fish rots from the head." For another eight months, America will be guided by one of the stupidest fish heads ever washed up by the Potomac (Teeter M.H. The St. Petersburg. Times, 01.04.2008).

Говоря о возможности переноса русских пословиц на англоязычную почву, следует учитывать и экстралингвистические факторы, в том числе требование политической корректности. В группе риска оказываются собственно уничижительные наименования этносов, а также идиомы, которые могут задеть те или иные меньшинства, например незваный гость хуже татарина или горбатого могила исправит. В русском языке эти выражения не являются оскорбительными, поскольку в результате лежащего в основе фразеологизации процесса семантического опрощения элементы фразеологизмов утрачивают прямые значения. Однако в переводе эти значения оживают, делая выражения неприемлемыми с точки зрения современной этики, что не всегда учитывается в англоязычных описаниях русской культуры:

(12) Not for Mom the old Russian adage «An uninvited guest is worse than an invading Tatar» (Bremzen A. Mastering the Art of Soviet Cooking).

(13) Khrushchev once turned on Neizvestny and exclaimed, "Only death will cure the hunchback!" (Salisbury H.I. The Soviet Union: The Fifty Years).

При включении в текст иноязычной идиомы следует также учитывать специфику ее подтекста. Так, в русском языке выражение черного кобеля не отмоешь до бела не имеет расистского или шовинистского подтекста, а его калька на английский язык в новом лингвокультурном окружении приобретает его.

Введение в иноязычный текст пословиц, содержащих непереводимые идионимы (Взялся за гужн-не говори, что не дюж!; За семь верст киселя хлебать и др.) в целом неце- 
лесообразно, поскольку потребует пояснений, нивелирующих стилистический эффект. Кроме того, нежелательно и калькирование пословицы, особенно в тех случаях, когда буквальный перевод искажает оригинал (достаточно вспомнить хрущевскую кузькину мать, которую безуспешно пытались опознать западные переводчики). Приводимая ниже калька русской идиомы на ней / нем нет лица, которая встречается в англоязычном романе В. Набокова - пограничный случай (впрочем, нередкий у этого автора) и скорее воспринимается как художественный прием:

(14) "On her there was no face," as Russians say to describe an expression of utter dejection (Nabokov V. Ada).

Инолингвокультурный контекст возможно ввести и посредством локализации идиом языка описания:

(14) take care of the pence and the pounds will take care of themselves $\rightarrow$ take care of the copec, and the rubles will take care of themselves (Carr J. A Northern Summer).

Этот прием, эффективно создающий местный колорит и минимально затрудняющий восприятие текста, оказался достаточно востребованным в различных жанрах иноязычного описания русской культуры. При этом локализации подвергаются общеизвестные фразеологизмы, из которых предпочтение отдается фразеологическим сращениям и единствам, а подстановка в них ксенонима порождает еще и ярко выраженный юмористический эффект:

(15) to keep up with the Joneses $\rightarrow$ Or perhaps the owners ... had built a garage to keep up with the Brezhnevs (Newby E. Big Red Train Ride);

(16) to rob Peter to pay Paul $\rightarrow$ Robbing Pyotr to pay Pavel: the working generation is being called upon to plug the fiscal hole in the Russian pension system (www.israelnationalnews.com, 20.04.2018);

(17) to out-herod Herod $\rightarrow$ If that happened, pundits would surely argue that he [Trump] was trying to out-Putin Putin (https://www.salon.com, 18.01.2017).

Помимо фразеологизмов, инолингвокультурный контекст может быть представлен и другими прецедентными текстами русской культуры: a) песнями:

(18) 'Shiroka strana moya rodnaya' ('O vast is my country!'), the people are singing (Bremzen A. Mastering the Art of Soviet Cooking);

б) кинофильмами:

(19) Circus, a Hollywood-style musical comedy (Bremzen A. Mastering the Art of Soviet Cooking);

в) произведениями художественной литературы:

(20) 'Did you remember to stop by the house on Povarskaya Street where Natasha from War and Peace lived?' (Bremzen A. Mastering the Art of Soviet Cooking).

При этом можно отметить складывающийся корпус прецедентных текстов, значимых для описания русской культуры. Частотны в нем произведения А.П. Чехова:

(21) “To Moscow, to Moscow, to Moscow!” said Nick, reciting Chekhov (Wilson M. Meeting at a Far Meridian);

(22) "Huddled on our bony refugee sofa I read Chekhov's Three Sister's and whimpered along with the characters: 'To Moscow ... to Moscow'" (Bremzen A. Mastering the Art of Soviet Cooking);

(23) “To Moscow, to Moscow!" - this has always been the yearning phrase proclaimed by characters in novels by Anton Chekhov. "To Moscow!", they say full of longing because life is supposedly better in Moscow, where they anticipated work and opportunity. But in the end, they never go to Moscow. In June 2016 I, too, told myself: “To Moscow!" but with one difference - I actually went! (Ludwig A. https:// culturalvistas.org).

В этот корпус также входит литературное наследие Л.Н. Толстого, хотя и в существенно усеченном объеме. Так, весьма остроумен «твит» Мэтью Иглесиаса, в котором «русская политическая тема» репрезентирована литературной аллюзией - вполне узнаваемой цитатой из романа «Анна Каренина» Bce смешалось в доме Облонских:

(24) All was confusion in the house of the Trumps (Yglesias M., https://twitter.com/mattyglesias).

Однако, как отмечает Г.С. Морсон, одной из самых цитируемых в мировой литературе является фраза Все счастливые семьи 
похожи друг на друга, каждая несчастливая семья несчастлива по-своему, открывающая роман [Morson, 2007, с. 35]. Она включена в паремиологические словари, многочисленные сборники цитат и афоризмов:

(25) All happy families resemble one another, each unhappy family is unhappy in its own way (The Yale Book of Quotations, 2006, p. 766; The Oxford Dictionary of Quotations 1999, p. 779).

Встречается эта цитата и в произведениях аутентичной англоязычной художественной литературы:

(26) He laughed again, and this time Elaynora joined him. "Happy families are all alike," she said. Jack finished the Anna Karenina line. "Unhappy families are each unhappy in their own way" (Pollack R. The Fissure King).

Убедительным доказательством закрепления этой цитаты в мировой культуре являются ее обыгрывания и трансформации, подразумевающие уверенность автора в узнаваемости цитаты массовым читателем:

(27) Meetings. To twist an old statement, all happy meetings are like one another, every unhappy meeting is unhappy in its own fashion (Snow C.P. The Sleep of Reason).

Примечателен также пример использования данной цитаты как метафоры, поясняющей различия в вычислении уравнений обыкновенных разностных и частных производных:

(28) Ordinary differential equations are a happy family; perhaps they do not resemble each other but, at the very least, we can write them in a single overarching form $y^{\prime}=f(t, y)$ and treat them by a relatively small compendium of computational techniques. (True, upon closer examination, even ODEs are not all the same $<\ldots>$. How many happy families will survive the deconstructing attention of a mathematician?) (Iserles, 2009, p. 139).

Знаменитое высказывание Л.Н. Толстого послужило толчком для рассуждений Р. Элиор о социальной природе женщин:

(29) At all times and in all communities, happy women have resembled one another in that freedom of choice $<$... $>$ were available to them to a greater or lesser degree (Elior, 2008, p. 14).
Оно легло в основу «принципа Анны Карениной» (Anna Karenina principle), заключающегося в том, что в любой сфере жизнедеятельности к неудаче ведет огромное разнообразие факторов и причин, успех же возможен лишь в одном случае, а именно: если удалось избежать всех возможных многочисленных рисков [Bornmann, Werner, 2012].

Прецедентным в мировой культуре стало и имя Анна Каренина, несущее широкий спектр смыслов-ассоциаций: «саморазрушающая страсть», «трагедия», «плохая мать». Например:

(30) I didn't relay any messy Anna Karenina details; I just said, after turning off my phone: "Your mother has kind of a headache this morning, so she is going to lie down for a bit (COCA: Karenina);

(31) The girl had a small dark face surrounded by a fur hat from which her gold eyes looked out. I thought of Anna Karenina at the railway station; her first appearance there and the last, because her end was foreshadowed in the beginning (COCA: Karenina);

(32) "Aren't you overdoing the Anna Karenina act just a bit?” (COCA: Karenina).

Другие имена из того же романа используются в качестве прецедентных гораздо реже:

(33) 'Felix? Darling, is that you? Door's open! Is Karenin out there? Bring the bastard in" (Smith Z. NW);

(34) Karenin was on the mat. Felix gathered him sloppily into his arms. The cat's huge weight kept displacing itself: it wasn't possible to hold up its backside, belly and neck at the same time, something always fell through the gap. He whispered into its ear - "All right, K" - and stepped inside (Smith Z. NW).

Они обычно выступают лишь в качестве дополнения к имени Анна Каренина и не функционируют как автономная аллюзия:

(35) Not since Lydia Bennet eloped with Mr. Wickham, not since Anna Karenina ran off with Count Vronsky, has such a hue and cry been heard about purloined affections (COCA: Karenina);

(36) Despite what I'd imagined, she was in her mid-thirties, and the light summer dress she was wearing made her look even younger. $<\ldots>$ A sort of Anna Karenina, but without Vronsky or the screech of carriage wheels (COCA: Karenina). 
Среди других прецедентных имен из произведений русской классики можно отметить следующие:

Обломов:

(37) ... for her I was another Oblomov, another lout (COCA: Oblomov);

(38) The radio announcers, however, were used to filling dead air in any circumstance, albeit with a languor that would have been the envy of Oblomov (COCA: Oblomov);

Раскольников:

(39) Approaching a darkened doorway, she felt like Rodion Raskolnikov skulking through shadows after the murder of an elderly pawnbroker... or Anna Karenina, determining in a moment of desperation to fling herself beneath the carriage of an onrushing train (COCA: Raskolnikov);

(40) I like how it addresses us as potential criminals who roll out of bed each morning feeling like Raskolnikov (COCA: Raskolnikov);

\section{Карамазов:}

(41) It's hard to witness, kids being sick, kids with mitochondrial disorder, kids being brave, et cetera. I feel like Ivan Karamazov or somebody like that. See how fat I'm getting? (COCA: Karamazov);

(42) A Dostoevsky-like aura surrounds one episode of the movie. Sounding very much like Ivan Karamazov in The Brothers Karamazov, Mickey asks a member of his family, "If there is a God, why is there so much evil?" (COCA: Karamazov).

Англоязычные авторы, создавая инолингвокультурный контекст пытаются вербально имитировать когнитивные структуры, специфичные для русского менталитета. Так, в следующих примерах авторы вводят образы, основанные на специфически русских сравнениях - гастрономических и политических:

(43) In the evenings, she strolled down the Neva embankment, its austere neoclassical buildings the color of cucumber flesh, omelet batter, sour-creamed borsch (Melnik K. Snow in May);

(44) Bushy Brezhnevian eyebrows were overtaking his forehead. A small island of hair, still blond, was moored at the geographical center of his pate (Shteingart G. The Russian Debutante's Handbook).

Имитироваться может как когнитивная, так и поверхностная структура высказывания. В последнем случае мы имеем синтаксическое уподобление, также отсылающее читателя к внешней лингвокультуре:
(45) "I'm under observation as we speak," said Mr. Rybakov, peering under Vladimir's desk (Shteingart G. The Russian Debutante's Handbook).

Инолингвокультурный контекст может имитировать «чужой» дискурс. Примечателен пример, в котором реплика, открывающая рассказ, «погружает» читателя в советское дискурсивноепространство, известное своей категоричностью, прямолинейностью и пренебрежением к принципам кооперативного общения.

(46) "Grazhdanka, it's forbidden to sit here. Follow me" (Melnik K. Love, Italian Style, or in Line for Bananas).

Категорический императив здесь вложен в уста представителя власти. Аналогична риторика персонажа П. Саймонс:

(47) "Tania, be quiet and sit down," Papa ordered his daughter. "It's about to begin. Irina, you, too. Sit" (Simons P. The Bronze Horseman).

Как видно из приведенного обзора, инолингвокультурный контекст может вербализоваться широким спектром средств, варьируясь в своей прозрачности для инокультурного читателя и выполняя в нарративе разные функции (культурологическую, стилистическую, эзотерическую и др.).

\section{Заключение}

\section{и перспективы исследования}

В контексте глобализации, в том числе «глобанглизации», то есть установления английского языка в роли глобальной lingua franca, повсеместно наблюдается переход с родного языка на язык-посредник: на английском общаются между собой бизнесмены, ученые, туристы; на нем пишут новости и инокультурную художественную литературу. Это привело не только к изменению значимости и представительности практики англоязычного описания внешней культуры, но и к его перестройке, вызванной такими факторами, как (1) большая частотность соответствующих дискурсивных событий, выступающих прецедентами и способствующих выработке единых принципов дискурсивного поведения, и (2) перемены в общемировой дискурсивной ситуации, отличительной чертой которой является противоборство тенденций к унификации и 
упрощению средств коммуникации, с одной стороны, и к сохранению уникальности и идентификации дискурсивных сообществ, с другой. Таким образом, ранее относительно разрозненные и немногочисленные тексты вторичной культурной ориентации сегодня обретают черты единого дискурса, цементируемого как содержательно-тематическим стержнем, так и определенными дискурсивными стратегиями.

На этом этапе представляется оправданным введение в исследовательскую программу интерлингвокультурологии корпусных технологий. Корпусная методика жанрово-дискурсивных исследований апробирована в ряде работ [Ильинова, Кочетова, 2017; Колокольникова, 2010] и, несомненно, позволит не только верифицировать накопленные данные, но и получить новые результаты.

Так, работа с национальными корпусами позволяет оценить место исследуемого дискурса в общем дискурсивном пространстве современного английского языка путем отслеживания частотности и функционирования его суперструктурных маркеров, что показывает проведенное исследование лексико-семантического поля HOUSE. Возможности современных национальных корпусов также позволяют сравнить функционирование инолингвокультурных маркеров в разных национальных вариантах английского языка, различающихся как внутриязыковыми тенденциями, так и идеолого-политическим фоном, что иллюстрирует развитие русизма czar / tsar в британском и американском стандартах английского языка.

К перспективам исследования следует отнести создание корпуса текстов англоязычного описания русской культуры для системного изучения специфики данного дискурса.

\section{СПИСОК ЛИТЕРАТУРЫ}

Голубкова Е. Е., 2012. Дискурсивная составляющая в исследованиях по когнитивной семантике // Вестник Московского государственного лингвистического университета. № 638 . C. $90-98$.

Ильинова Е. Ю., Кочетова Л. А., 2017. Динамика репрезентации процессуальной составляющей спортивного события в диахроническом корпусе // Вестник Волгоградского государственного университета. Серия 2, Языкознание. Т. 16, № 2. C. 47-57. DOI: https://doi.org/ 10.15688/jvolsu2.2017.2.5.

Кабакчи В. В., 2007. Типология текста иноязычного описания культуры и инолингвокультурный субстрат // Лингвистика текста и дискурсивный анализ: традиции и перспективы. СПб. : Изд-во СПбГУЭФ. С. 51-70.

Колокольникова М. Ю., 2010. Дискурс-анализ и корпусный анализ в исследованиях в области исторической дискурсологии // Известия Саратовского университета. Серия. Филология. Журналистика. Т. 10, вып. 2. С. 3-6.

Кунин А. В., 1964. О переводе английских фразеологизмов в англо-русском фразеологическом словаре // Тетради переводчика. Вып. 2. М. : Междунар. отношения. С. 3-20.

Bornmann L., Werner M., 2012. The Anna Karenina principle: A way of thinking about success in science // Journal of the American Society for Information Science and Technology. Vol. 63, № 10. P. 2037-2051.

Morson G. S., 2007. Anna Karenina in Our Time: Seeing More Wisely. New Haven ; London : Yale univ. press, cop. 263 p.

\section{ИСТОЧНИКИ}

$B N C$ - British National Corpus. URL: https://corpus. byu.edu/bnc/ (accessed 7 March 2018)

Carr J., 1806. ANorthern Summer; or Travels round the Baltic, through Denmark, Sweden, Russia, Prussia, and part of Germany, in the year 1804. Glasgow : D. M'Kenzie. 300 p.

COCA - Corpus of Contemporary American English. URL: https://corpus.byu.edu/coca/ (accessed 7 March 2018)

Elior R., 2008. Dybbuks and Jewish Women in Social History, Mysticism and Folklore. Jerusalem ; New York: Urim Publications. $125 \mathrm{p}$.

Iserles A., 2009. A First Course in the Numerical Analysis of Differential Equations. Cambridge University Press. 459 p.

LDCE - Longman Dictionary of Contemporary English. URL: https://www.ldoceonline.com (accessed 7 March 2018)

Roget's International Thesaurus of English Words and Phrases / ed. by C. O. S. Mawson. New York : Thomas Y. Crowell, 1922. URL: www.bartleby.com/ 110/ (accessed 7 March 2018)

The OxfordDictionary ofQuotations/ed. byE. M. Knowles. Oxford UniversityPress, 1999. $1136 \mathrm{p}$.

The Yale Book of Quotations / ed. by F. R. Shapiro. Yale University Press, 2006. 1067 p. 
Е.В. Белоглазова, В.В. Кабакчи. Дискурс англоязычного описания русской культуры

\section{REFERENCES}

Golubkova E.E., 2012. Discourse component in cognitive semantic research. Vestnik Moskovskogo gosudarstvennogo lingvisticheskogo universiteta [MSLUBulletin: theHumanities], no. 638, pp. 90-98.

Ilyinova E.Yu., Kochetova L.A., 2017. Dynamics of process constituent representation of a sport event in diachronic corpus. Vestnik Volgogradskogo gosudarstvennogo universiteta. Seriya 2. Yazykoznanie [Science Journal of Volgograd State University. Linguistics], vol. 16, no. 2, pp. 47-57. DOI: https://doi.org/10.15688/jvolsu2.2017.2.5.

Kabakchi V.V., 2007. Typology of foreign-cultureoriented texts and foreign-culture substrate. Lingvistika teksta i diskursivnyy analiz: traditsii $i$ perspektivy [Text Linguistics and Discourse Analysis: Traditions and Prospects]. Saint Petersburg, Izd-vo SPbGUEF, pp. 51-70.

Kolokolnikova M.Yu., 2010. Discourse analysis and corpus analysis in historical discourse studies. Izvestiya Saratovskogo universiteta. Seriya. Filologiya. Zhurnalistika [Izvestiya of Saratov University. New Series. Philology. Journalism], vol. 10, iss. 2, pp. 3-6.

Kunin A.V., 1964. On translating English idioms in EnglishRussian idiomatic dictionary. Tetradi perevodchika [Translator's Notes]. Moscow, Mezhdunarodnye otnosheniya Publ., no. 2, pp. 3-20.

Bornmann L., Werner M., 2012. The Anna Karenina principle: A way of thinking about success in science. Journal of the American Society for Information Science and Technology, vol. 63, no. 10 , pp. 2037-2051.
Morson G.S., 2007. Anna Karenina in Our Time: Seeing More Wisely. New Haven; London, Yale univ. press. $263 \mathrm{p}$.

\section{SOURCES}

British National Corpus. URL: https://corpus.byu. edu/bnc/ (accessed 7 March 2018)

Carr J., 1806. A Northern Summer; or Travels round the Baltic, through Denmark, Sweden, Russia, Prussia, and part of Germany, in the year 1804. Glasgow, D. M'Kenzie. 300 p.

Corpus of Contemporary American English. URL: https://corpus.byu.edu/coca/ (accessed 7 March 2018)

Elior R., 2008. Dybbuks and Jewish women in social history, mysticism and folklore. Jerusalem; New York, Urim Publications. $125 \mathrm{p}$.

Iserles A., 2009. A first course in the numerical analysis of differential equations. Cambridge University Press. 459 p.

Longman Dictionary of Contemporary English. URL: https://www.ldoceonline.com (accessed 7 March 2018)

Mawson C.O.S. (ed.), 1922. Roget's International Thesaurus of English Words and Phrases. New York, Thomas Y. Crowell. URL: www.bartleby. com/110/ (accessed 7 March 2018)

Knowles E.M. (ed.), 1999. The Oxford Dictionary of Quotations. Oxford, Oxford University Press. $1136 \mathrm{p}$.

Shapiro F.R. (ed.) The Yale Book of Quotations. Yale University Press, 2006. 1067 p.

\section{Information about the Authors}

Elena V. Beloglazova, Doctor of Sciences (Philology), Professor of Department of Theory of Language and Translation Studies, Saint Petersburg State University of Economics, Moskatelny Lane, 4, 191023 Saint Petersburg, Russia, Beloglazova.e@unecon.ru, https://orcid.org/0000-0002-0267-9614

Viktor V. Kabakchi, Doctor of Sciences (Philology), Professor of Department of Theory of Language and Translation Studies, Saint Petersburg State University of Economics, Moskatelny Lane, 4, 191023 Saint Petersburg, Russia, vkabakchi@gmail.com, https://orcid.org/0000-0003-2164-7017

\section{Информация об авторах}

Елена Владимировна Белоглазова, доктор филологических наук, профессор кафедры теории языка и переводоведения, Санкт-Петербургский государственный экономический университет, пер. Москательный, 4, 191023 г. Санкт-Петербург, Россия, Beloglazova.e@unecon.ru, https:// orcid.org/0000-0002-0267-9614

Виктор Владимирович Кабакчи, доктор филологических наук, профессор кафедры теории языка и переводоведения, Санкт-Петербургский государственный экономический университет, пер. Москательный, 4, 191023 г. Санкт-Петербург, Россия, vkabakchi@gmail.com, https://orcid.org/0000-0003-2164-7017 